\title{
BMJ Open A cross-sectional study on upright heart rate and BP changing characteristics: basic data for establishing diagnosis of postural orthostatic tachycardia syndrome and orthostatic hypertension
}

Juan Zhao, ${ }^{1}$ Zhenhui Han, ${ }^{2}$ Xi Zhang, ${ }^{2}$ Shuxu Du, ${ }^{3}$ Angie Dong Liu, ${ }^{4}$ Lukas Holmberg, ${ }^{4}$ Xueying Li, ${ }^{5}$ Jing Lin, ${ }^{1}$ Zhenyu Xiong, ${ }^{2}$ Yong Gai, ${ }^{2}$ Jinyan Yang, ${ }^{1}$ Ping Liu, ${ }^{1}$ Chaoshu Tang, ${ }^{6}$ Junbao Du, ${ }^{1,7}$ Hongfang Jin ${ }^{1}$

To cite: Zhao J, Han Z, Zhang $\mathrm{X}$, et al. A crosssectional study on upright heart rate and $\mathrm{BP}$ changing characteristics: basic data for establishing diagnosis of postural orthostatic tachycardia syndrome and orthostatic hypertension. BMJ Open 2015;5:e007356. doi:10.1136/bmjopen-2014007356

- Prepublication history for this paper is available online. To view these files please visit the journal online (http://dx.doi.org/10.1136/ bmjopen-2014-007356).

$\mathrm{JZ}$ and ZH contributed equally.

Received 2 December 2014 Revised 23 April 2015 Accepted 26 April 2015

CrossMark

For numbered affiliations see end of article.

Correspondence to

Dr Junbao Du;

junbaodu1@126.com

\section{ABSTRACT}

Objective: We aimed to determine upright heart rate and blood pressure (BP) changes to suggest diagnostic criteria for postural orthostatic tachycardia syndrome (POTS) and orthostatic hypertension (OHT) in Chinese children.

Methods: In this cross-sectional study, 1449 children and adolescents aged 6-18 years were randomly recruited from two cities in China, Kaifeng in Henan province and Anguo in Hebei province. They were divided into two groups: 844 children aged 6-12 years (group I) and 605 adolescents aged 13-18 years (group II). Heart rate and BP were recorded during an active standing test.

Results: 95th percentile $\left(\mathrm{P}_{95}\right)$ of $\delta$ heart rate from supine to upright was $38 \mathrm{bpm}$, with a maximum upright heart rate of 130 and $124 \mathrm{bpm}$ in group I and group II, respectively. $\mathrm{P}_{95}$ of $\delta$ systolic blood pressure (SBP) increase was $18 \mathrm{~mm} \mathrm{Hg}$ and $P_{95}$ of upright SBP was $132 \mathrm{~mm} \mathrm{Hg}$ in group I and $138 \mathrm{~mm} \mathrm{Hg}$ in group II. $\mathrm{P}_{95}$ of $\delta$ diastolic blood pressure (DBP) increase was $24 \mathrm{~mm} \mathrm{Hg}$ in group I and $21 \mathrm{~mm} \mathrm{Hg}$ in group II, and $\mathrm{P}_{95}$ of upright DBP was $89 \mathrm{~mm} \mathrm{Hg}$ in group I and $91 \mathrm{~mm} \mathrm{Hg}$ in group II.

Conclusions: POTS is suggested when $\delta$ heart rate is $\geq 38 \mathrm{bpm}$ (for easy memory, $\geq 40 \mathrm{bpm}$ ) from supine to upright, or maximum heart rate $\geq 130 \mathrm{bpm}$ (children aged $6-12$ years) and $\geq 125$ bpm (adolescents aged 13-18 years), associated with orthostatic symptoms. $\mathrm{OHT}$ is suggested when $\delta$ SBP (increase) is $\geq 20 \mathrm{~mm} \mathrm{Hg}$, and/or $\delta$ DBP (increase) $\geq 25 \mathrm{~mm} \mathrm{Hg}$ (in children aged 6-12 years) or $\geq 20 \mathrm{~mm} \mathrm{Hg}$ (in adolescents aged 13-18 years) from supine to upright; or upright $\mathrm{BP} \geq 130 / 90 \mathrm{~mm} \mathrm{Hg}$ (in children aged $6-12$ years) or $\geq 140 / 90 \mathrm{~mm} \mathrm{Hg}$ (in adolescents aged $13-18$ years).

\section{INTRODUCTION}

Orthostatic intolerance (OI) is a group of diseases induced by standing and relieved by

\section{Strengths and limitations of this study}

- Orthostatic intolerance is one of the most common causes for syncope in children and adolescents, seriously affecting their daily life and school studies.

- The distribution characteristics of upright heart rate and blood pressure in children and adolescents evidenced by large-sampled data was lacking.

- This study suggested distribution characteristics of heart rate and blood pressure changes during an active standing test in children and adolescents.

- The upright heart rate and blood pressure changes were useful to suggest diagnostic criteria for postural orthostatic tachycardia syndrome or orthostatic hypertension in children and adolescents.

- This study was conducted in the north of China. To ascertain whether the results are applicable to children and adolescents in other areas will need multicentre studies.

recumbence, and includes symptoms such as dizziness, headache, palpitations, nausea, abdominal pain, concentration difficulties, hyperventilation, presyncope and even syncope. ${ }^{1}$ It is one of the most common causes for syncope in children and adolescents, seriously affecting their daily life and school studies, ${ }^{2}$ and places heavy mental and economic burdens on families. ${ }^{3-7}$ Postural orthostatic tachycardia syndrome (POTS), vasovagal syncope and orthostatic hypertension (OHT) make up the main components of OI.

The active standing test is one of the most important diagnostic methods for OI. During the test, clinical symptoms, heart rate and blood pressure (BP) changes can be 
recorded from supine to upright position. However, the active standing test-based diagnostic criteria for children and adolescents with POTS or OHT have mainly been sourced from the data of adults due to the absence of large-sampled epidemiological data from children. In 1993 , the POTS diagnostic criteria were reported as an increased heart rate of $\geq 30 \mathrm{bpm}$ or a maximum heart rate of $\geq 120 \mathrm{bpm}$ without $\mathrm{BP}$ decline within $10 \mathrm{~min}$ after the individual stands upright from a supine position. ${ }^{8}$ These diagnostic criteria were previously used in most studies on children and adolescents in this area. ${ }^{9-11}$ The OHT diagnostic criterion was proposed by Fessel and Robertson ${ }^{12}$ in 2006 as an increased systolic blood pressure $(\mathrm{SBP}) \geq 20 \mathrm{~mm} \mathrm{Hg}$ without requirements for diastolic blood pressure (DBP) after standing compared with BP at supine position. However, up to now, the OHT diagnostic criterion has not been used for diagnosing children.

Children and adolescents are at a special growth period. Their cardiovascular development is immature and presents different features compared with adults, such as a smaller stroke volume, thinner vessel walls, larger vessel diameter and incomplete nervous system regulation. ${ }^{13}$ Their heart rates are faster and their BPs are lower than in adults. In particular, the exact changes of heart rate and BP from supine to upright are larger than in adults and the normal range of heart rate and $\mathrm{BP}$ varies with ages. Therefore, the diagnostic criteria for adults are sometimes not suitable for children and adolescents. In a consensus statement, Freeman et $a l^{14}$ indicated that increased heart rate should be raised by at least $40 \mathrm{bpm}$ in POTS diagnosis of adolescents aged between 12 and 19 years. Singer et $a l^{15}$ reported that the 95th percentile $\left(\mathrm{P}_{95}\right)$ of heart rate change was $42.9 \mathrm{bpm}$ in normal children and adolescents aged between 8 and 19 years, using head-up tilt test (HUTT). However, large sample-sized evidence for the criteria of POTS in children is lacking and OI diagnostic criteria for Chinese children have not been established. Therefore, the present study was designed to determine the normalvalues of heart rate and $\mathrm{BP}$ changes during the standing test in children and adolescents in China, with a specific focus on the age-related and gender-related differences.

\section{METHODS}

\section{Participants}

In this cross-sectional study, we randomly selected five schools in Kaifeng, in Henan province, and Anguo, in Hebei province in China, from October 2012 to January 2013. We randomly recruited students from each grade of the schools $(198,113,118,158,127,130,154,97,67$, 107, 106 and 74 students from grades 1-6 of elementary schools and grades 1-6 of high schools, respectively). Totally, 1449 children and adolescents aged 6-18 years were sampled for this study. All students took the active standing test. They were divided into two groups according to age: 844 children aged between 6 and 12 years in group I (434 boys and 410 girls) and 605 adolescents aged between 13 and 18 years in group II (319 boys and 286 girls). Their medical history was taken and physical examination was carried out for the study participants. Those participants with heart and pulmonary vascular diseases or with a history of taking drugs in the prior 3 months were excluded through history of illness, BP measurement, physical examination and ECG.

\section{Basic anthropometric indexes}

Anthropometric study was performed using the same medical scales (Q241, Zhejiang Anbo Medical Devices Co, Ltd) according to a standard measurement method. The instrument was calibrated prior to application and its quality was controlled regularly. The weight and height were measured and the body mass index (BMI) was calculated as $\mathrm{kg} / \mathrm{m}^{2}$.

\section{Protocol for the active standing test}

The children were tested with an active standing test. A quiet environment with a room temperature of $22^{\circ} \mathrm{C}$ and dim light was required during the active standing test. ${ }^{16}$ The children laid quietly at supine position for at least $10 \min ^{517}$ before the basal BP and heart rate were recorded. Then, they were asked to stand upright on their own for $10 \mathrm{~min}$, and their heart rate and BP were monitored during the whole test using a Dash 2000 Multi-Channel Physiologic Monitor (General Electric, Schenectady, New York, USA), which automatically and dynamically displayed heart rate using three-lead ECG and intermittent oscillometric BP. We used the most stable heart rate in a $60 \mathrm{~s}$ interval as the participant's heart rate during this period. The heart rate was sampled every minute during the $10 \mathrm{~min}$ period. The sampling time of the heart rate was $1 \mathrm{~min}$. The maximum upright heart rate was defined as the maximum heart rate during the $10 \mathrm{~min}$ of active standing. In the active standing test, we derived four BPs for each participant, one supine BP and three standing BPs at 3, 6 and $9 \mathrm{~min}$, respectively, after standing. The children recovered recumbence immediately in those cases where dizziness, headache, nausea, paleness or other discomfort occurred while their heart rate and $\mathrm{BP}$ were being observed. Appropriate cuffs were used throughout the research.

\section{Statistical methods}

Measurement data were analysed using SPSS V.13.0 (SPSS, Chicago, Illinois, USA) for statistical analysis and expressed in mean $\pm \mathrm{SD}$. After homogeneity test of variance in both groups, independent sample student $t$ test was performed for analysing the differences between the two age groups. Repeated measure analysis was used to analysing the differences for heart rate and BP in different positions and times. $\chi^{2}$ Test was performed for sex ratio comparison and $\mathrm{p}<0.05$ was deemed as statistically significant. For data in skewed or unknown distribution, a percentile approach built on a confidence level was 
Table 1 Baseline characteristics of children

\begin{tabular}{lllllll}
\hline Group & $\mathbf{n}$ & Age, years & Male/female & Height, $\mathbf{c m}$ & Weight, $\mathbf{~ g}$ & Body mass index, $\mathbf{~ k g} / \mathbf{m}^{\mathbf{2}}$ \\
\hline 6-12 years & 844 & $9 \pm 2$ & $434 / 410$ & $141 \pm 12$ & $36 \pm 11$ & $17.65 \pm 3.21$ \\
13-18 years & 605 & $15 \pm 2^{*}$ & $319 / 286$ & $163 \pm 8^{*}$ & $53 \pm 10^{*}$ & $20.11 \pm 3.13^{*}$ \\
\hline
\end{tabular}

Values are mean \pm SD.

${ }^{*}$ Denotes $p$ value $<0.01$.

used for determination of normal value range. We selected the $\mathrm{P}_{95}$ as a normal threshold for the change of heart rate and $\mathrm{BP}$ from supine to standing. ${ }^{18-20}$

\section{RESULTS}

\section{Clinical features of participants}

The study comprised of 1449 children and adolescents aged between 6 and 18 years. The mean height, weight and BMI in the children aged 6-12 years was higher than in the adolescents aged between 13 and 18 years $(\mathrm{p}<0.05$, table 1$)$. No participant with missing data was found in either index.

It was found that heart rate after standing was significantly greater than that at supine position in both groups (figure $1, \mathrm{p}<0.001$ ). BP after standing was also higher than BP at supine position in both groups (figure 2, $\mathrm{p}<0.001$ ).

\section{Features of haemodynamic changes}

In all of the participants, the supine heart rate was 84 $\pm 12 \mathrm{bpm}$, maximum upright heart rate $107 \pm 14 \mathrm{bpm}$ and $\delta$ heart rate $22 \pm 9 \mathrm{bpm}$. The supine heart rate and maximum upright heart rate significantly differed between the two groups $(\mathrm{p}<0.001)$ but the $\delta$ heart rate did not $(\mathrm{p}=0.632)$ (figure 1 and table 2$)$.

The supine SBP was $110 \pm 10 \mathrm{~mm} \mathrm{Hg}$ and upright SBP, $118 \pm 10 \mathrm{~mm} \mathrm{Hg}$, and $\delta \mathrm{SBP}$ increase was $8 \pm 7 \mathrm{~mm} \mathrm{Hg}$ in all of the participants. The supine DBP was $65 \pm 9 \mathrm{~mm} \mathrm{Hg}$ and upright DBP, $76 \pm 9 \mathrm{~mm} \mathrm{Hg}$, and $\delta$ DBP increase was $11 \pm 7 \mathrm{~mm} \mathrm{Hg}$ in all the children and adolescents. There were significant differences in supine, upright and $\delta$ DBP between both groups $(\mathrm{p}<0.001)$ (figure 1 and table 2).

The appearance of 0 l symptoms in the active standing test During the active standing test, there were 269 (18.6\%) children and adolescents reporting about OI symptoms, and they recovered recumbence immediately (light headedness 130 (9.0\%), headache $130(9.0 \%)$, fatigue $123(8.5 \%)$, long breath $74(5.1 \%)$, vertigo 69 $(4.8 \%)$, blurred vision $64(4.4 \%)$, palpitations 56 $(3.9 \%)$ and other discomfort $68(4.7 \%))$. No one fainted during the test. From the analysis, we found
Figure 1 (A) Changes in heart rate (bpm) in the active standing test. The heart rate was recorded from supine to $10 \mathrm{~min}$ of standing in children and adolescents.

(B) Changes in systolic blood pressure (SBP, $\mathrm{mm} \mathrm{Hg}$ ) in the active standing test. The SBP was recorded at supine position and after standing in children and adolescents. (C) Changes in diastolic blood pressure (DBP, $\mathrm{mm} \mathrm{Hg}$ ) in the active standing test. The DBP was recorded at supine position and after standing in children and adolescents. DBP, diastolic blood pressure; SBP, systolic blood pressure.

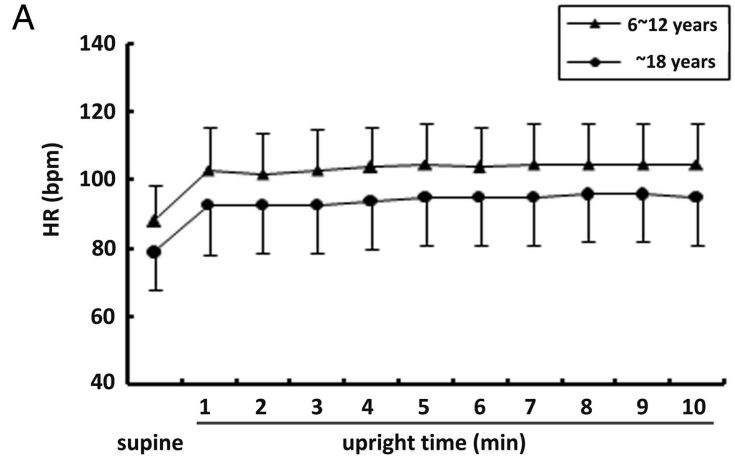

B

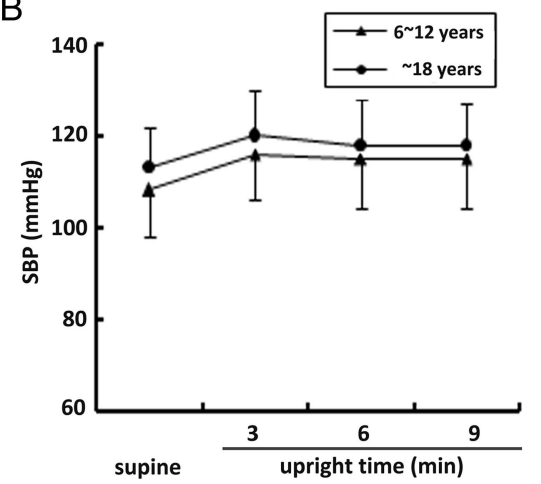

C

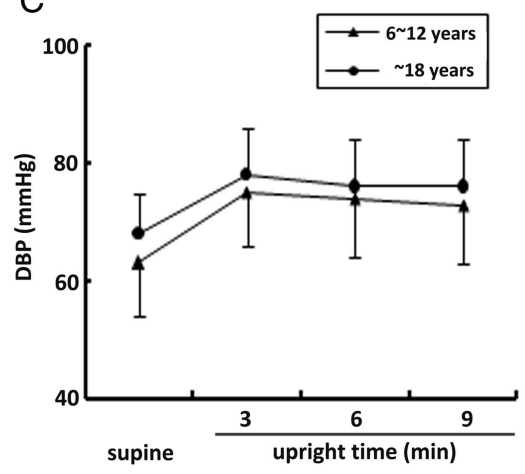




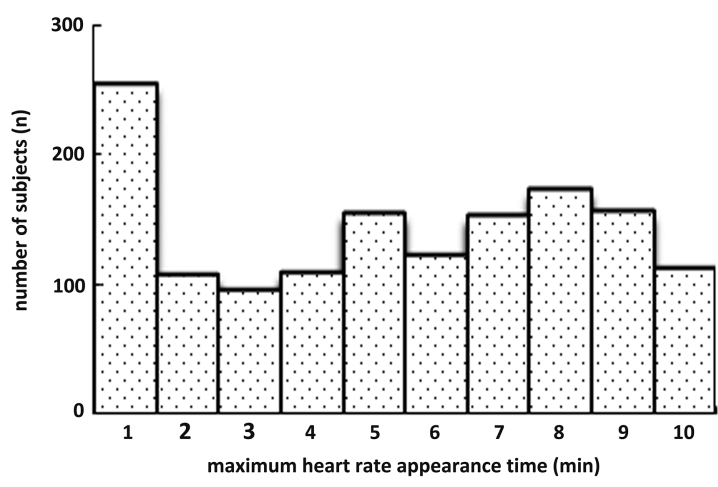

Figure 2 The distribution chart of time required for reaching the maximum heart rate after standing of all participants.

that the children with symptoms during the standing test were older than those without symptoms $(12 \pm 2$ vs $10 \pm 2$ years, $\mathrm{t}=-9.667, \mathrm{p}<0.001)$. Also, children with symptoms during the standing test had more frequent previous OI symptoms $(103 / 269$ vs $277 / 1180$, $\left.\chi^{2}=24.852, \mathrm{p}<0.001\right)$, higher supine heart rate $(88 \pm 11$ vs $86 \pm 10 \mathrm{bpm}, \mathrm{t}=2.258, \mathrm{p}=0.024)$, faster heart rate maximum ( $111 \pm 11$ vs $109 \pm 11 \mathrm{bpm}, \mathrm{t}=2.274, \mathrm{p}=0.023)$ and greater BMI $\left(18.973 \pm 3.662\right.$ vs $17.876 \pm 3.221 \mathrm{~kg} / \mathrm{m}^{2}$, $\mathrm{t}=-4.571, \mathrm{p}<0.001)$, than those without symptoms during the standing test.

In our study participants, 287 children had an OI history. Forty-two children among them had a syncope history. The children who had an OI history were older than those without a history $(12 \pm 2$ vs $11 \pm 2$ years, $\mathrm{t}=-3.824, \mathrm{p}<0.001)$. The differences in supine heart rate $(85 \pm 12$ vs $88 \pm 11 \mathrm{bpm}, \mathrm{t}=1.199, \mathrm{p}=0.231)$, standing heart rate maximum $(108 \pm 12$ vs $110 \pm 11 \mathrm{bpm}, \quad \mathrm{t}=1.059$, $\mathrm{p}=0.290$ ), supine BP (SBP $110 \pm 9$ vs $109 \pm 10 \mathrm{~mm} \mathrm{Hg}$, $\mathrm{t}=-0.491, \mathrm{p}=0.624)$, supine DBP $(65 \pm 11$ vs $64 \pm 9 \mathrm{~mm} \mathrm{Hg}$, $\mathrm{t}=-1.048, \mathrm{p}=0.295)$ and upright $\mathrm{BP}$ (SBP $120 \pm 15$ vs 117 $\pm 10 \mathrm{~mm} \mathrm{Hg}, \mathrm{t}=-1.141, \mathrm{p}=0.260)$, supine DBP $(77 \pm 17$ vs $76 \pm 9 \mathrm{~mm} \mathrm{Hg}, \mathrm{t}=-0.658, \mathrm{p}=0.514)$ between the two groups were not significant.

Percentile values of maximum heart rate, $\delta$ heart rate, BP and $\delta$ BP increase in the active standing test

As shown in table $3, \mathrm{P}_{95}$ of maximum upright heart rate was $130 \mathrm{bpm}$ in group I and $124 \mathrm{bpm}$ in group II. Since $\delta$ heart rate did not differ between the two groups, we combined the data of the two groups in analysing $\delta$ heart rate from supine to upright position and showed that $\mathrm{P}_{95}$ of $\delta$ heart rate was $38 \mathrm{bpm}$.

$\mathrm{P}_{95}$ of upright SBP was $132 \mathrm{~mm} \mathrm{Hg}$ in group I and $138 \mathrm{~mm} \mathrm{Hg}$ in group II. Since $\delta \mathrm{SBP}$ increase from supine to upright position did not differ between the two groups, we combined the data of the two groups in analysing $\delta$ SBP increase $\mathrm{P}_{95}$ and showed that $\delta$ SBP increase $\mathrm{P}_{95}$ was $18 \mathrm{~mm} \mathrm{Hg}$. $\mathrm{P}_{95}$ of upright $\mathrm{DBP}$ was $89 \mathrm{~mm} \mathrm{Hg}$ in group I and $91 \mathrm{~mm} \mathrm{Hg}$ in group II, and $\mathrm{P}_{95}$ of $\delta$ DBP increase from supine to upright position

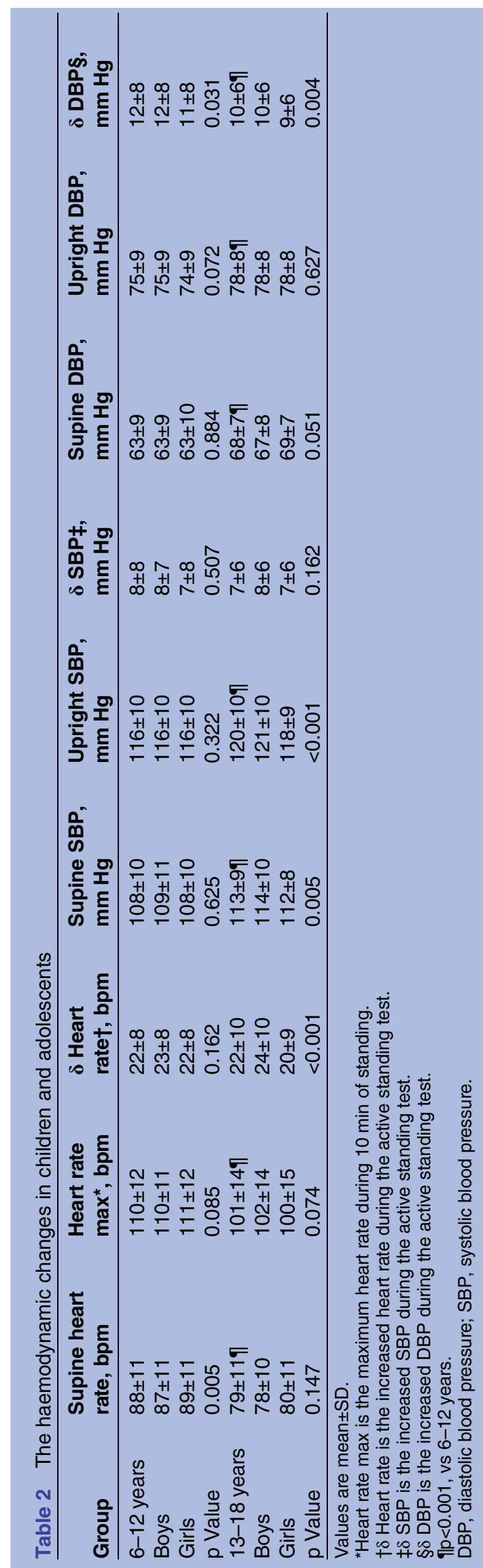


Table 3 The percentage of heart rate and blood pressure in the active standing test

\begin{tabular}{lrrrrr}
\hline & \multicolumn{5}{l}{ Percentile } \\
\cline { 2 - 6 } Indices & 5th & 10th & 50th & 90th & 95th \\
\hline Heart rate max ${ }^{*}, \mathrm{bpm}$ & & & & & \\
6-12 years & 92 & 96 & 110 & 125 & 130 \\
13-18 years & 76 & 85 & 101 & 118 & 124 \\
$\quad \delta$ Heart rate†, bpm & 8 & 12 & 23 & 33 & 38 \\
Upright SBP, mm Hg & & & & & \\
6-12 years & 100 & 103 & 116 & 128 & 132 \\
13-18 years & 105 & 108 & 119 & 133 & 138 \\
$\delta$ SBP mm Hg & -4 & -1 & 8 & 15 & 18 \\
Upright DBP, mm Hg & & & & & \\
6-12 years & 60 & 64 & 75 & 86 & 89 \\
13-18 years & 65 & 68 & 78 & 87 & 91 \\
$\delta$ DBP§, mm Hg & & & & & \\
6-12 years & -1 & 2 & 12 & 21 & 24 \\
13-18 years & -1 & 2 & 10 & 18 & 21 \\
\hline
\end{tabular}

*Heart rate max is the maximum heart rate during the $10 \mathrm{~min}$ of standing.

$\dagger \delta$ Heart rate is the increased heart rate during the active standing test.

$\ddagger \delta$ SBP is the increased SBP during the active standing test. $\S \delta$ DBP is the increased DBP during the active standing test DBP, diastolic blood pressure; SBP, systolic blood pressure.

was $24 \mathrm{~mm} \mathrm{Hg}$ in group I and $21 \mathrm{~mm} \mathrm{Hg}$ in group II (table 3).

\section{Time to reach maximum heart rate in the active standing} test

The median time to reach maximum heart rate was 5 (1-10) min, where maximum heart rate occurred in 255 children within $1 \mathrm{~min}$ after standing, accounting for $17.6 \%$ of the participants (figure 2).

\section{DISCUSSION}

Currently, great attention is being paid to OI in children and adolescents. Although some scholars believe that the HUTT is the golden standard examination to evaluate an individual's response to postural changes, the active standing test has its own advantages and is preferred in many clinical settings since it is easy, practicable and reliable. ${ }^{21}$ Comparative studies on the active standing test and HUTT have discovered that both methods have similar sensitivity, and that the active standing test has even higher specificity than HUTT ( $79 \%$ vs $23 \%$ ) when increased heart rate is $\geq 30 \mathrm{bpm}$, as a POTS diagnostic criterion. ${ }^{22}$ Thus, in the present study, we investigated the normal values of heart rate and BP changes during the active standing test and explored the POTS and OHT diagnostic criteria for children and adolescents in China.

Since adult POTS criteria were used by Schondrof and Low in 1993, the increased value of heart rate $\geq 30 \mathrm{bpm}$ or maximum heart rate $\geq 120 \mathrm{bpm}$ within $10 \mathrm{~min}$ from supine to standing or from supine to head-up tilt has been applied in many studies for children and adolescents. However, children and adolescents are in a special growth and development period. Their cardiovascular development is immature and they need an increased heart rate to ensure enough haemoperfusion. ${ }^{23}$ In addition, heart rate is mainly controlled by the nervous system. The excitement of the sympathetic nervous system allows rapid heart beat and excitement of the parasympathetic nervous system allows slow heart beat. Normally, the sympathetic and parasympathetic nervous systems are balanced, but in children and adolescents, they are not yet fully developed, and the dominant sympathetic nervous system leads to an increased heart rate. ${ }^{13}$ This physiologically fast heart beat, however, will gradually be reduced to the level of a normal adult. Heart rate and BP are related to age, sex, height, weight and race. Long-term observations have shown that BP varies with age, and that before puberty, BP in boys and girls increases rapidly over time.

Recent studies have shown that the diagnostic specificity was reduced when adult POTS and OI diagnostic criteria were applied on children and adolescents. Some studies showed that the change in heart rate from supine to upright position in children and adolescents was up to $40-50 \mathrm{bpm}^{5}{ }^{724}$ For instance, Skinner et a $\bar{l}$ showed that 307 adolescents aged between 15 and 17 years had a heart rate change from -1 to $+48 \mathrm{bpm}$ at 5 min standing. Furthermore, Yamaguchi et $a l^{25}$ found that the development maturity influenced heart rate change from supine to upright position. 173 school children aged between 6 and 18 years had greater heart rate change than non-pubertal children from supine to upright position (34 (9) bpm vs 29 (8) bpm, p<0.001). Therefore, an increase in heart rate $\geq 35 \mathrm{bpm}$ as diagnostic criterion for children and adolescents with POTS is recommended. ${ }^{26}$ Recently, Freeman $e t a l^{14}$ and Singer et $a l^{15}$ recommended $40 \mathrm{bmp}$ as a POTS diagnostic criterion in children and adolescents by taking into account the variability of heart rate. Singer et $a l^{15}$ studied 106 children and adolescents aged between 8 and 19 years with HUTT for $5 \mathrm{~min}$ and showed that maximum heart rate $\geq 130 \mathrm{bpm}$ in children aged $\leq 13$ years, and $\geq 120 \mathrm{bpm}$ in adolescents aged $\geq 14$ years, were the diagnostic criteria of maximum heart rate in children and adolescents with POTS. Up to now, large sample-sized studies of heart rate and BP change during the standing test are still needed.

We found that $18.6 \%$ of children and adolescents reported about OI symptoms during the standing test and they recovered recumbence immediately. Also, children with symptoms during the standing test were older than those without symptoms, which was in accordance with the fact that OI was common in older children. We noticed that children with symptoms during the standing test had faster supine heart rates than those without symptoms during the standing test, suggesting that the underlying mechanisms for OI symptoms likely involve the increased sympathetic nervous system excitability. ${ }^{1}{ }^{12}$ 
Our study results showed that the maximum change of heart rate from supine to upright was $52 \mathrm{bpm}$, and the change in the two groups did not differ $(\mathrm{p}=0.632)$. However, we found that the change of heart rate was not affected by age, sex, height, weight and BMI, in children and adolescents. This suggested that the same diagnostic criterion could be applied on children and adolescents with a large span of age variation. Our results showed that POTS should be suggested in children and adolescents when a heart rate change from supine to upright position $\geq 38 \mathrm{bpm}$ (for easy memory, $\geq 40 \mathrm{bpm}$ ); and/or maximum heart rate $\geq 130 \mathrm{bpm}$ at upright position within $10 \mathrm{~min}$ in group I and $\geq 125 \mathrm{bpm}$ at upright position in group II, when there is a history of clinical orthostatic symptoms.

Since adult OHT was proposed by Fessel and Robertson ${ }^{12}$ in 2006, it has been mostly applied in analysing recurrent cardiovascular risk in elderly patients with hypertension. ${ }^{27}$ Pathophysiologically speaking, OHT reflects sympathetic activity and microvascular and cardiac remodelling, and it has become a new risk factor for cardiovascular disease. Thomas $e t a t^{8}$ showed that risks of hypertension were increased substantially within eight follow-up years in young adults with increased $\mathrm{BP}>5 \mathrm{~mm} \mathrm{Hg}$ after standing. However, there has been no definite diagnostic criterion for OHT.

In our study, the BP was reduced only in a small number of cases, but was stable or increased in most children and adolescents after standing. The SBP change from supine to upright position did not differ significantly between the groups, but the DBP change did. Based on our present results, with $\mathrm{BP}$ at supine position as baseline $\mathrm{BP}$ and $\mathrm{BP}$ at $3 \mathrm{~min}$ after standing as orthostatic BP, and according to the percentile analysis of the BP data, OHT needs to be suggested when (1) $\delta$ SBP increase from supine to upright position within $3 \mathrm{~min} \geq 20 \mathrm{~mm} \mathrm{Hg}$, or $\delta \mathrm{DBP}$ increases $\geq 25 \mathrm{~mm} \mathrm{Hg}$ in children aged $6-12$ years and $\geq 20 \mathrm{~mm} \mathrm{Hg}$ in adolescents aged 13-18 years; or (2) an increase in BP from supine to upright position $\geq 130 / 90 \mathrm{~mm} \mathrm{Hg}$ (for children aged $6-12$ years) or $\geq 140 / 90 \mathrm{~mm} \mathrm{Hg}$ (for adolescents aged 13-18 years) within $3 \mathrm{~min}$. For convenience in clinical use, we suggested $130\left(\mathrm{P}_{91.5}\right) / 90\left(\mathrm{P}_{95.2}\right)$ and $140\left(\mathrm{P}_{96.6}\right) /$ $90\left(\mathrm{P}_{93.8}\right) \mathrm{mm} \mathrm{Hg}$ instead of 132/89 and 138/91 $\mathrm{mm} \mathrm{Hg}$ for children and adolescents, respectively. The determination of the cut-off value for OHT is controversial. However, in some epidemiological studies, the $\mathrm{P}_{95}$ as a normal threshold for disease was used. ${ }^{18-20}$ With those references, we also used the $\mathrm{P}_{95}$ in our present study. More importantly, the OHT diagnosis should depend on the comprehensive situation of the patients including the upright change of $\mathrm{BP}$, the upright absolute $\mathrm{BP}$ and clinical OI symptoms, as previously indicated. ${ }^{26} \quad 27$ Further investigations need to be conducted to confirm previous findings and discover new insights of the situation as a BP measurement result.

In addition, recent studies recommend that observation time limit of HUTT should be shorter than 5 min after postural change. ${ }^{29}$ The reason is that changes in heart rate and BP have explicit performance within 5 min after standing, but lack significance between 6 and $10 \mathrm{~min}$ after standing. Nevertheless, in some studies, at least 2, 5 and $10 \mathrm{~min}$ after standing were included in the HUTT because some patients showed a delayed tachycardia. The results of our study found that the median time of reaching maximum heart rate was 5 (1-10) $\mathrm{min}$ in the active standing test in children and adolescents. Therefore, we recommend the orthostatic heart rate and $\mathrm{BP}$ to be measured within $10 \mathrm{~min}$ in children. ${ }^{30}$

\section{Limitations}

Our present study still has some limitations. For example, though the study sample was large, the study was from the north of China. Whether the results are suitable to children and adolescents in other areas still needs validation through multicentre studies. As for diagnostic criterion, we still need a derivation cohort followed by a validation cohort to confirm these findings. The criteria of upright heart rate and BP came from the active standing test, and whether they fit HUTT or not also needs further research. Up to now, the significance of OHT in childhood is still incompletely understood.

\section{CONCLUSIONS}

Children have significant distribution characteristics of heart rate and BP during standing tests, which would be useful for the consideration of POTS when $\delta$ heart rate $\geq 38 \mathrm{bpm}$ (for easy memory, $\geq 40 \mathrm{bpm}$ ), or maximum heart rate $\geq 130 \mathrm{bpm}$ for children aged 6-12 years and $\geq 125 \mathrm{bpm}$ for adolescents aged 13-18 years within $10 \mathrm{~min}$ from moving from supine to upright position, together with clinical orthostatic symptoms. OHT should be defined as a SBP increase $\geq 20 \mathrm{~mm} \mathrm{Hg}$, and/or DBP increase $\geq 25 \mathrm{~mm} \mathrm{Hg}$ (children aged 6-12 years) or $\geq 20 \mathrm{~mm} \mathrm{Hg}$ (adolescents aged 13-18 years), within $3 \mathrm{~min}$ from supine to upright position; or $\mathrm{BP} \geq 130 / 90 \mathrm{~mm} \mathrm{Hg}$ (children aged $6-12$ years) or $\geq 140 / 90 \mathrm{~mm} \mathrm{Hg}$ (children aged $6-12$ years) after standing.

\section{Author affiliations}

${ }^{1}$ Department of Pediatrics, Peking University First Hospital, Beijing, People's Republic of China

${ }^{2}$ Department of Pediatrics, Kaifeng Children's Hospital, Henan, People's Republic of China

${ }^{3}$ Department of Pediatrics, The Capital Medical University, Shijitan Hospital, Beijing, People's Republic of China

${ }^{4}$ Department of Medical and Health Sciences, Linköping University, Linköping, Sweden

${ }^{5}$ Department of Medical Statistics, Peking University First Hospital, Beijing, People's Republic of China

${ }^{6}$ Department of Physiology and Pathophysiology, Peking University Health Sciences Centre, Beijing, People's Republic of China

${ }^{7}$ Key Laboratory of Cardiovascular Medicine, Ministry of Education, Beijing, People's Republic of China

Contributors $\mathrm{HJ}, \mathrm{JD}, \mathrm{CT}$, ZH and JZ designed the research. JZ, ZH, JY, JL, $P L, X Z, Z X, Y G, S D, X L$ and $J Z$ participated in the acquisition of the data. $Z H$, $X L, J D, A D L, L H$ and $J Z$ analysed the data. JZ, ZH, XL, HJ and JD interpreted the results of the experiments. JZ, ZH, JD, CT, ADL, JY, JL, PL, XZ, ZX, YG, 
SD, XL and HJ drafted the manuscript. JZ, ZH, HJ, CT, JD, ADL and LH revised the manuscript. All the authors have read and approved the final manuscript.

Funding The work was supported by grants from the National Twelfth Five-Year Plan for Science and Technology Support (2012BAI03B03) the Major Basic Research Project of China (2012CB517806, 2011CB503904 and 2012BA103B03) and the National Natural Science Foundation of China (81121061).

Competing interests None declared.

Patient consent Obtained

Ethics approval Peking University First Hospital, Beijing 100034, People's Republic of China.

Provenance and peer review Not commissioned; externally peer reviewed.

Data sharing statement No additional data are available.

Open Access This is an Open Access article distributed in accordance with the Creative Commons Attribution Non Commercial (CC BY-NC 4.0) license which permits others to distribute, remix, adapt, build upon this work noncommercially, and license their derivative works on different terms, provided the original work is properly cited and the use is non-commercial. See: http:// creativecommons.org/licenses/by-nc/4.0/

\section{REFERENCES}

1. Stewart JM. Orthostatic intolerance in pediatrics. J Pediatr 2002;140:404-11.

2. Antiel RM, Risma JM, Grothe RM, et al. Orthostatic intolerance and gastrointestinal motility in adolescents with nausea and abdominal pain. J Pediatr Gastroenterol Nutr 2008;46:285-8.

3. Mathisa CJ, Low PA, lodice V, et al. Postural tachycardia syndrome current experience and concepts. Nat Rev Neurol 2012:8:22-34.

4. Ojha A, Chelimsky TC, Chelimsky G. Comorbidities in pediatric patients with postural orthostatic tachycardia syndrome. J Pediatr 2011;158:20-3.

5. Skinner JE, Driscoll SW, Porter CB, et al. Orthostatic heart rate and blood pressure in adolescents: reference ranges. J Child Neurol 2010;25:1210-5.

6. Grubb BP. Postural tachycardia syndrome. Circulation 2008;117:2814-7.

7. Low PA, Opfer-Gehrking TL, Textor SC, et al. Postural tachycardia syndrome (POTS). Neurology 1995;45:S19-25.

8. Schondorf R, Low P. Idiopathic postural orthostatic tachycardia syndrome: an attenuated form of acute pandysautonomia. Neurology 1993;43:132-7.

9. Stwart JM, Ocon AJ, Clarke D, et al. Defects in cutaneous angiotensin-converting enzyme 2 and angiotensin-(1-7) production in postural tachycardia syndrome. Hypertension 2009;53:767-74.

10. Zhang F, Li X, Ochs T, et al. Midregional pro-adrenomedullin as a predictor for therapeutic response to midodrine hydrochloride in children with postural orthostatic tachycardia syndrome. J Am Coll Cardiol 2012;60:315-20.

11. Burkhardt BE, Fischer PR, Brands CK, et al. Exercise performance in adolescents with autonomic dysfunction. J Pediatr 2011;158:15-19.
12. Fessel J, Robertson D. Orthostatic hypertension: when pressor reflexes overcompensate. Nat Clin Pract Nephrol 2006;2:424-31.

13. Janz KF, Dawson JD, Mahoney LT. Predicting heart growth during puberty: The Muscatine Study. Pediatrics 2000;105:E63.

14. Freeman R, Wieling W, Awelrod FB, et al. Consensus statement on the definition of orthostatic hypotension, neurally mediated syncope and the postural tachycardia syndrome. Clin Auton Res 2011;21:69-72

15. Singer W, Sletten DM, Opfer-Gehrking TL, et al. Postural tachycardia in children and adolescents: what is abnormal? J Pediatr 2012;160:222-6.

16. Jenner DA, English DR, Vandongen R, et al. Environmenta temperature and blood pressure in 9-year-old Australian children $J$ Hypertens 1987;5:683-6.

17. Brewster JA, Garland EM, Biaggioni I, et al. Diurnal variability in orthostatic tachycardia: implications for the postural tachycardia syndrome. Clin Sci (Lond) 2012;122:25-31.

18. National High Blood Pressure Education Program Working Group on High Blood Pressure in Children and Adolescents. The fourth report on the diagnosis, evaluation, and treatment of high blood pressure in children and adolescents. Pediatrics 2004;114:555-76.

19. Boyd JC, Lacher DA. The multivariate reference range: an alternative interpretation of multi-test profiles. Clin Chem 1982;28:259-65.

20. Zheng $\mathrm{MH}$, Shi KQ, Fan YC, et al. Upper limits of normal for serum alanine aminotransferase levels in Chinese Han population. PloS ONE 2012;7:e43736.

21. Brown SJ, Bryant M, Mundel T, et al. Human ventilatory efficiency and respiratory sinus arrhythmia during head-up tilt. $J$ Physiol Pharmacol 2008;59:771-80.

22. Plash WB, Diedrich A, Biaggioni I, et al. Diagnosing postura tachycardia syndrome: comparison of tilt testing compared with standing haemodynamics. Clin Sci (Lond) 2013;124:109-14.

23. Cui W, Roberson DA, Chen Z, et al. Systolic and diastolic time intervals measured from Doppler tissue imaging: normal values and Z-score tables, and effects of age, heart rate, and body surface area. J Am Soc Echocardiogr 2008;21:361-70.

24. Horam WJ, Roscelli JD. Establishing standards of orthostatic measurements in normovolemic adolescents. AM J Dis Child 1992;146:845-51.

25. Yamaguchi $\mathrm{H}$, Tanaka $\mathrm{H}$, Adachi $\mathrm{K}$, et al. Beat-to-beat blood pressure and heart rate response to active standing in Japanese children. Acta Paediatr 1996;85:577-83.

26. Weiling W, Karemaker JM. Measurement of heart rate and blood pressure to evaluate disturbances in neurocardiovascular control. In: Mathias CJ, Bannister R, eds. Autonomic failure. A textbook of clinical disorders of the autonomic nervous system. Oxford: Oxford University Press, 2006:196-210.

27. Fan $\mathrm{XH}$, Wang $\mathrm{Y}$, Sun $\mathrm{K}$, et al. Disorder of orthostatic blood pressure response are associated with cardiovascular disease and target organ damage in hypertension patients. Am J Hypertens 2010;23:823-37.

28. Thomas RJ, Liu K, Jacobs DR Jr, et al. Positional change in blood pressure and 8-year risk of hypertension: the CARDIA study. Mayo Clin Proc 2003;78:951-8.

29. Nardo CJ, Chambless LE, Light KC, et al. Descriptive epidemiology of blood pressure response to change in body position. The ARIC study. Hypertension 1999;33:1123-9.

30. Sheriff DD, Nadland IH, Toska K. Hemodynamic consequences of rapid changes in posture in humans. J Appl Physiol 2007; 103:452-8. 